•研究报告・

\title{
新疆吉木萨尔县蝴蝶群落多样性
}

\author{
徐志峰 1,2 钟 问 $^{1,2}$ 张东康 ${ }^{1}$ 胡红英 ${ }^{1,2 *}$ \\ 1 (新疆大学生命科学与技术学院, 乌鲁木齐 830046) \\ 2 (新疆生物资源基因工程重点实验室，乌鲁木齐 830046)
}

摘要: 蝴蝶作为指示生物, 被广泛地应用于生物多样性监测及环境质量评估。探究新疆吉木萨尔县蝴蝶群落多样 性, 可为当地蝴蝶多样性的保护及环境监测提供基础数据。本研究采用样线法在新疆吉木萨尔县选取山前荒漠、 农田、山地草原、山地森林、亚高山草甸 5 种不同的生境类型, 对蝴蝶种类和群落多样性进行调查。共记录蝴蝶4,401 号, 隶属于7科 26 属 38 种。其中蛱蝶科有 9 属 12 种, 为优势科; 粉蝶科的个体数最多, 占比 $55.01 \%$; 绢蝶科、风蝶科 和弄蝶科的种类数和个体数最少, 均为单科种, 是该地区的稀有类群。对不同生境蝴蝶群落多样性和相似度分析 比较的结果显示: 5 种生境中多样性指数从高到低依次为亚高山草甸、山地森林、山地草原、农田及山前荒漠, 其 中山地森林和亚高山草甸的相似性系数较高, 达到 0.77 , 山前荒漠和山地草原的相似性系数最低, 为 0.37 。蝴蝶物 种数及多样性指数随海拔的增加呈上升趋势。蝴蝶群落随月份发生变化, 蝴蝶种类和数量在 5 月发生、7月达到峰 值。蝶类个体数在3年内呈下降趋势。研究结果表明, 蝴蝶物种的组成和多样性与生境类型具有密切联系, 保护生 态环境, 维持该地区植物群落的多样性、降低人为干扰程度是保护蝶类多样性的关键。

关键词: 蝴蝶监测; 生境; 多样性; 种群动态; 环境保护

\section{Diversity of butterfly communities in Jimusaer County, Xinjiang}

\author{
Zhifeng $\mathrm{Xu}^{1,2}$, Wen Zhong ${ }^{1,2}$, Dongkang Zhang ${ }^{1}$, Hongying $\mathrm{Hu}^{1,2^{*}}$ \\ 1 College of Life Sciences and Technology, Xinjiang University, Urumqi 830046 \\ 2 Xinjiang Key Laboratory of Biological Resources and Genetic Engineering, Urumqi 830046
}

\begin{abstract}
Butterflies are indicator species that are widely used in biodiversity monitoring and environmental quality assessments. Here, we assessed the diversity of the butterfly community in Jimusaer County, Xinjiang, to guide recommendations for the protection of local butterfly diversity and environmental monitoring. We surveyed the species and community diversity of butterflies in five different habitat types, including Piedmont desert, farmland, mountain grassland, mountain forest, and subalpine meadow in Jimusar County, Xinjiang using the line transect sampling method from May to August in 2016-2018. We collected a total of 4,401 individuals belonging to 26 genera, 7 families, and 38 species. Nymphalidae was the dominant family with 9 genera and 12 species. Pieridae had the largest number of individuals, accounting for $55.01 \%$ of the total recorded. Pamassiidae, Papilioidae, and Hesperiidae had the fewest number of species and individuals_each family had only one species, which were rarely observed in the study region. By analysing and comparing the diversity and similarity of butterfly communities in different habitats, we found that diversity was greatest in sub-alpine meadows and lowest in Piedmont desert. Mountain forest, mountain grassland, and farmland had intermediate levels of diversity. The similarity coefficient was highest between mountain forests and sub-alpine meadows (0.77) and lowest between Piedmont deserts and mountain grasslands (0.37). Butterfly species richness and diversity increased with elevation. We also found that the number of butterfly species and individuals changed over the course of a year and were highest from May to July. The total number of individuals decreased over the three-year study period. Our results show that butterfly community composition and diversity are closely related to habitat types. Therefore, protecting the ecological environment, maintaining a diversity of plant communities, and reducing the degree of human
\end{abstract}


disturbance in the region are key to conserving butterfly diversity.

Key words: butterfly monitoring; habitat; biodiversity; population dynamics; environmental protection

开发并利用指示生物进行环境动态监测成为 全球生物多样性保护关注的焦点之一(Pimm et al, 1995; 曹铭昌等, 2013; Mihindukulasooriy et al, 2014; Xu et al, 2017; 姬婷婷, 2019)。蝴蝶对环境变化敏感, 易于观察捕捉, 且有关的生物学及分类学知识较为 普及, 有利于作为指示生物, 应用于生物多样性监 测及环境质量评估(Kremen, 1992; Nelson, 2007; László \& Schmitt, 2011; Li et al, 2011; 马方舟等, 2018)。对特定环境区域内蝶类群落组成及多样性进 行研究, 不仅可以丰富物种资源数据, 还可为生态 监测提供理论依据(房丽君等, 2013)。

吉木萨尔县位于东天山北部, 其境内山脉是天 山山脉的重要组成部分。新疆天山东部山地作为内 陆干旱区的巨大 “湿岛”, 具有丰富的生物资源和独 特的生物区系(熊嘉武等, 2015)。张金等(2013)调查 了天山东部蝶类的多样性及其垂直分布, 共记录蝴 蝶7科43属63种。目前对吉木萨尔县域内蝴蝶资源 尚未进行过系统研究, 缺乏对该地蝴蝶群落多样性 的深入研究, 阻碍了对该地区蝶类资源的开发利 用。

近年来, 专家学者们对于蝴蝶资源的调查主要 集中在物种组成、区系分析等方面(胡冰冰等, 2010; 旦智措等, 2018), 从时空维度、生境类型等方面综 合探讨蝴蝶多样性的研究报道较少。根据生态环境
部蝴蝶多样性观测网络的统一要求(马方舟等, 2018), 本研究于2016年至2018年5-8月, 对新疆吉 木萨尔县的蝴蝶物种资源进行了本底调查, 并对不 同生境类型、不同时空维度下的蝴蝶群落进行了多 样性指数、相似性指数检验, 旨在补充东天山蝴蝶 物种数据, 揭示不同因素与蝴蝶分布的内在联系, 为该地区蝴蝶物种多样性保护提出建议, 并为该地 区的环境监测提供基础数据。

\section{研究方法}

\section{1 研究区域概况}

研究区域位于新疆维吾尔自治区昌吉回族自 治州境内天山北麓东段 $\left(89^{\circ} 01^{\prime} 01^{\prime \prime}-89^{\circ} 05^{\prime} 08^{\prime \prime}\right.$ E, $43^{\circ} 42^{\prime} 03^{\prime \prime}-43^{\circ} 54^{\prime} 20^{\prime \prime} \mathrm{N}$ ), 属于温带大陆性干旱半干 旱气候区, 年均气温 $7.9^{\circ} \mathrm{C}$, 最高气温 $40.8^{\circ} \mathrm{C}$, 最低 气温 $-29.8^{\circ} \mathrm{C}$, 年均降水量 $203.7 \mathrm{~mm}$, 年均日照时数 2,641.3 h (傅玮东等, 2007)。研究区域内的植被主要 包括乔木、禾草、旱生灌木、垫状植被等(表1)。

\section{2 研究地点}

根据不同植被类型，并结合海拔梯度变化，在 研究区域内选择5种生境类型作为研究地点(表1)。

(1)山前荒漠。气候干燥、植被稀少、郁闭度较 低、生境较为相似, 以盐柴类半灌木、小半灌木为 主要建群种。主要植被有猪毛菜(Salsola collina)、

表1 吉木萨尔县代表性生境类型

Table 1 Typical habitat types in Jimusaer County

\begin{tabular}{|c|c|c|c|c|}
\hline $\begin{array}{l}\text { 生境类型 } \\
\text { Habitat type }\end{array}$ & $\begin{array}{l}\text { 地点 } \\
\text { Monitoring sites }\end{array}$ & $\begin{array}{l}\text { 经纬度 } \\
\text { Locality }\end{array}$ & $\begin{array}{l}\text { 海拔 } \\
\text { Altitude (m) }\end{array}$ & $\begin{array}{l}\text { 植被类型 } \\
\text { Vegetation type }\end{array}$ \\
\hline I & $\begin{array}{l}\text { 大有镇马家村 } \\
\text { Majia Village, Dayou Town }\end{array}$ & $\begin{array}{l}89^{\circ} 03^{\prime} 59^{\prime \prime} \mathrm{E} \\
44^{\circ} 54^{\prime} 13^{\prime \prime} \mathrm{N}\end{array}$ & $790-1,050$ & $\begin{array}{l}\text { 盐柴类半灌木、小半灌木 } \\
\text { Salt wood subshrub, undershrub }\end{array}$ \\
\hline II & $\begin{array}{l}\text { 大有镇小份子村 } \\
\text { Xiaofenzi Village, Dayou Town }\end{array}$ & $\begin{array}{l}89^{\circ} 02^{\prime} 38^{\prime \prime} \mathrm{E} \\
43^{\circ} 48^{\prime} 30^{\prime \prime} \mathrm{N}\end{array}$ & $990-1,358$ & $\begin{array}{l}\text { 一年一熟旱地作物 } \\
\text { Upland crop once a year }\end{array}$ \\
\hline III & $\begin{array}{l}\text { 渭户沟村深沟湾 } \\
\text { Shengou Bay, Weihu Gou Village }\end{array}$ & $\begin{array}{l}89^{\circ} 01^{\prime} 43^{\prime \prime} \mathrm{E} \\
43^{\circ} 47^{\prime} 03^{\prime \prime} \mathrm{N}\end{array}$ & $1,470-1,676$ & $\begin{array}{l}\text { 强旱生丛生禾草、旱生半灌木 } \\
\text { Xeric grasses, xeric subshrub }\end{array}$ \\
\hline IV & $\begin{array}{l}\text { 渭户沟村护林站南 } \\
\text { South of Forest Protection Station, Weihu Gou Village }\end{array}$ & $\begin{array}{l}89^{\circ} 01^{\prime} 01^{\prime \prime} \mathrm{E} \\
43^{\circ} 46^{\prime} 06^{\prime \prime} \mathrm{N}\end{array}$ & $1,748-1,903$ & $\begin{array}{l}\text { 雪岭云杉林、灌木 } \\
\text { Picea schrenkiana forest, shrubs }\end{array}$ \\
\hline V & $\begin{array}{l}\text { 渭户沟村护林站 } \\
\text { Forest Protection Station, Weihu Gou Village }\end{array}$ & $\begin{array}{l}88^{\circ} 59^{\prime} 25^{\prime \prime} \mathrm{E} \\
43^{\circ} 43^{\prime} 58^{\prime \prime} \mathrm{N}\end{array}$ & $1,852-2,112$ & $\begin{array}{l}\text { 强旱生丛生禾草、旱生半灌木 } \\
\text { Xeric grasses, xeric subshrub }\end{array}$ \\
\hline
\end{tabular}

I: 山前荒漠; II: 农田; III: 山地草原; IV: 山地森林; V: 亚高山草甸。 I, Piedmont desert; II, Farmland; III, Mountain grassland; IV, Mountain grassland; V, Subalpine meadow. 
骆驼蓬(Peganum harmala)、芨芨草(Achnatherum splendens)、芦苇(Phragmites australis)、苦豆子 (Sophora alopecuroides)、铃铛刺 (Halimodendron halodendron)、蒲公英(Taraxacum mongolicum)、千 叶萻(Achillea millefolium)等。

(2)农田。人为干扰极大, 且作物的类型随季节 和年份的不同而变化, 植被类型较为单一, 主要农 作物有玉米(Zea mays)、小麦 (Triticum aestivum)、马 铃薯(Solanum tuberosum)和豌豆(Pisum sativum)。田 边主要植物有白杨(Populus alba)、杏树(Armeniaca vulgaris)、白榆(Ulmus pumila)、糙苏 (Phlomis umbrosa)、大蓟(Cirsium japonicum)、芨芨草、苦豆 子、蒲公英、千叶蓄等。

(3)山地草原。人为开垦耕作较为严重, 生境明 显斑块化, 主要植被以强旱生从生禾草、旱生半灌 木为主, 包括大蓟、冷蒿(Artemisia friggida)、菖麻 (Urtica fissa)、大麻 (Cannabis sativa)、鸦葱 (Scorzonera ruprechtiana)、早熟禾(Poa annua)、蒲 公英等。

(4)山地森林。生境分布较为相似, 植被郁闭度 高, 人为干扰程度较轻, 主要以雪岭云杉(Picea schrenkiana)、西伯利亚落叶松林(Larix sibirica)形成 混交林, 林下有宽刺蓄薇(Rosa platyacantha)、天名 精 (Carpesium abrotanoides)、车轴草 (Galium odoratum)、菖麻、糙苏、大蓟、蓝花老鹳草(Geranium pseudosibiricum)、蒲公英等灌木及草本植物。

(5)亚高山草甸。海拔相对较高, 人为干扰较弱, 生境分布连续, 由强旱生丛生禾草、旱生半灌木等 低矮植物组成, 主要植物有蒲公英、菖麻、糙苏、 野草莓 (Fragaria ananassa) 、野蓄薇 (Rosa multiflora)、早熟禾等。

\section{3 调查方法}

样线观测法(马方舟等, 2018): 通过对吉木萨 尔县实地考察, 结合生境类型、植被类型、海拔梯 度等因素选取 5 条样线。在每种生境类型中选取 1 条 样线, 每条样线长 $2.0 \mathrm{~km}$, 海拔落差 $300 \mathrm{~m}$ (吴征镒, 1980; 熊嘉武等, 2015)。于2016-2018年每年的5-8 月每月观测 1 次，每次间隔20-30 d, 一般选择晴朗 无大风的天气。调查时间为蝶类活动频繁的 10:00-18:00。从起点开始使用GPS进行线路导航, 并在每个样段起始点进行打点标识。以 $1-1.5 \mathrm{~km} / \mathrm{h}$ 的速度徒步行走, 观测记录或网捕样线两边宽 2.5 $\mathrm{m}$ 、距地面 $5 \mathrm{~m}$ 范围内的蝴蝶(李果和李俊生, 2014; 马方舟等, 2018)。采集无法确定的蝴蝶标本装入三 角袋，记录采集时间、地点、采集人、样线、样段 等信息, 带回实验室。依据《中国蝶类志》(周尧, 2000)、《中国灰蝶志》(王敏和范骁凌, 2002)、《新 疆蝴蝶》(黄人金等, 1992)、《新疆昆虫原色图鉴》 (胡红英和黄人金鍑, 2012)、《中国蝴蝶图鉴》(武春 生和徐垤峰, 2017)等进行分类鉴定。

\section{4 数据分析}

对不同生境、海拔、月份蝴蝶群落多样性进行 比较, 包括物种数、Shannon-Wiener多样性指数 $\left(H^{\prime}\right)$ 、Margalef物种丰富度指数 $(R)$ 、均匀度指数 $(J)$ 、 Simpson优势度指数 $(D)$ 、相对多度 $(R a)$, Jaccard相似 性系数 $(I)$ 等(马克平等, 1994; 刘灿然等, 1998; Mulder et al, 2004)。各指数计算公式如下:

$$
\begin{aligned}
& H^{\prime}=-\sum p i \operatorname{lnpi}, p i=N i / N \\
& R=(S-1) / \ln N \\
& J=H^{\prime} / \ln S \\
& D=1-\sum_{i=1}^{s}\left(P_{i}\right)^{2} \\
& R a=N i / N \times 100 \% \\
& I=c /(a+b-c)
\end{aligned}
$$

式中, $S$ 为调查区内蝶类的种数, $P i$ 为第 $\mathrm{i}$ 种的个体数 占总个体数的比例, $N i$ 为种 $i$ 的个体数; $N$ 为所有种的 个体数, $a$ 为 $\mathrm{A}$ 生境物种数, $b$ 为 $\mathrm{B}$ 生境物种数, $c$ 为 $\mathrm{A}$ 、 $\mathrm{B}$ 两生境共有的物种数。当 $I$ 为 $0-0.25$ 时, 为极不相 似; $I$ 为 $0.25-0.50$ 时，为中等不相似; $I$ 为 $0.50-0.75$ 时, 为中等相似; $I$ 为 $0.75-1.00$ 时, 为极相似。定义个体 数所占比例超过所在生境个体总数 $5 \%$ 以上的为优 势种, $1 \%-5 \%$ 的为常见种, $0.5 \%-1 \%$ 的为少见种，不 足 $0.5 \%$ 的为稀有种。

使用Excel 2003和SPSS 19软件处理数据。

\section{2 结果}

\section{1 吉木萨尔县蝴蝶群落组成及数量特征}

调查中共采集蝶类标本 4,401 号, 经鉴定隶属 于7科26属38种(表2)。总体上看, 粉蝶科的云粉蝶 (Pieris Brassicae)、斑缘豆粉蝶(Colias erate), 蛱蝶 科的菖麻蛱蝶(Aglais urticae)在研究区域内分布较 广泛，3种蝴蝶个体数量占所有蝶类个体总数的 $46.72 \%$; 其中蛱蝶科种类占优，有9属 12 种，菖麻蛱 蝶为该科优势种，占蝶类总个体数的 $12.07 \%$ 。粉蝶 
表2 新疆吉木萨尔县不同生境蝴蝶的种类与数量

Table 2 Species and individual number of butterflies from different habitats in Jimusaer County, Xinjiang

\begin{tabular}{|c|c|c|c|c|c|c|c|}
\hline \multirow{2}{*}{$\begin{array}{l}\text { 种 } \\
\text { Species }\end{array}$} & \multicolumn{5}{|c|}{ 个体数 No. of individuals } & \multirow{2}{*}{$\begin{array}{l}\text { 总计 } \\
\text { Total }\end{array}$} & \multirow{2}{*}{$\begin{array}{l}\text { 相对多度 } \\
\text { Relative } \\
\text { abundance (\%) }\end{array}$} \\
\hline & $\begin{array}{l}\text { 山前荒漠 } \\
\text { Piedmont desert }\end{array}$ & $\begin{array}{l}\text { 农田 } \\
\text { Farmland }\end{array}$ & $\begin{array}{l}\text { 山地草原 } \\
\text { Mountain grassland }\end{array}$ & $\begin{array}{l}\text { 山地森林 } \\
\text { Mountain forest }\end{array}$ & $\begin{array}{l}\text { 亚高山草甸 } \\
\text { Subalpine meadow }\end{array}$ & & \\
\hline 斑缘豆粉蝶 Colias erate & 74 & 121 & 136 & 56 & 30 & 417 & 9.48 \\
\hline 豆粉蝶 Colias hyale & 2 & 11 & 10 & 15 & 19 & 57 & 1.30 \\
\hline 菜粉蝶 Pieris rapae & 11 & 155 & 118 & 51 & 12 & 347 & 7.88 \\
\hline 暗脉粉蝶 Pieris napi & 0 & 67 & 38 & 71 & 13 & 189 & 4.29 \\
\hline 黑纹粉蝶 Pieris melete & 0 & 4 & 10 & 8 & 1 & 23 & 0.52 \\
\hline 欧洲粉蝶 Pieris brassicae & 20 & 131 & 45 & 30 & 15 & 241 & 5.48 \\
\hline 云粉蝶 Pieris brassicae & 473 & 261 & 292 & 55 & 27 & 1,108 & 25.18 \\
\hline 绿云粉蝶 Pontia chloridice & 0 & 1 & 1 & 0 & 0 & 2 & 0.05 \\
\hline 箭纹云粉蝶 Pontia callidice & 0 & 0 & 0 & 30 & 7 & 37 & 0.84 \\
\hline 斑网蛱蝶 Melitaea didymoides & 5 & 0 & 0 & 2 & 41 & 48 & 1.09 \\
\hline 狄网蛱蝶 Melitaea didyma & 7 & 0 & 0 & 0 & 63 & 70 & 1.59 \\
\hline 大网蛱蝶 Melitaea scotosia & 0 & 0 & 0 & 0 & 2 & 2 & 0.05 \\
\hline 菖麻蛱蝶 Aglais urticae & 0 & 190 & 88 & 151 & 102 & 531 & 12.07 \\
\hline 单环蛱蝶 Neptis rivularis & 0 & 3 & 1 & 12 & 12 & 28 & 0.64 \\
\hline 灿福蛱蝶 Fabriciana adippe & 0 & 3 & 20 & 89 & 58 & 170 & 3.86 \\
\hline 福蛱蝶 Fabriciana niobe & 0 & 0 & 0 & 1 & 2 & 3 & 0.07 \\
\hline 小红蛱蝶 Vanessa cardui & 1 & 0 & 3 & 3 & 2 & 9 & 0.20 \\
\hline 绿豹蛱蝶 Argynnis paphia & 0 & 0 & 0 & 35 & 1 & 36 & 0.82 \\
\hline 潘豹蛱蝶 Pandoriana pandora & 0 & 0 & 0 & 1 & 0 & 1 & 0.02 \\
\hline 朱蛱蝶 Nymphalis xanthomelas & 0 & 1 & 2 & 0 & 16 & 19 & 0.43 \\
\hline 珠蛱蝶 Issoria lathonia & 0 & 0 & 0 & 3 & 1 & 4 & 0.09 \\
\hline 玄灰蝶 Tongeia fischeri & 0 & 0 & 0 & 0 & 3 & 3 & 0.07 \\
\hline 阿点灰蝶 Agrodiaetus amandus & 0 & 22 & 54 & 5 & 6 & 87 & 1.98 \\
\hline 璃灰蝶 Celastrina argiola & 0 & 34 & 28 & 2 & 4 & 68 & 1.55 \\
\hline 克豆灰蝶 Plebejus christophi & 69 & 7 & 11 & 4 & 0 & 91 & 2.07 \\
\hline 埃灰蝶 Eumedonia eumedon & 1 & 8 & 11 & 39 & 25 & 84 & 1.91 \\
\hline 萨眼灰蝶 Polyommatus sarta & 1 & 4 & 0 & 3 & 6 & 14 & 0.32 \\
\hline 多眼灰蝶 Polyommatus erotides & 0 & 0 & 18 & 2 & 9 & 29 & 0.66 \\
\hline 红珠灰蝶 Lycaeides argyrognomon & 0 & 0 & 1 & 0 & 0 & 1 & 0.02 \\
\hline 黄祄云眼蝶 Hyponephele lupina & 39 & 34 & 52 & 94 & 42 & 261 & 5.93 \\
\hline 居间云眼蝶 Hyponephele interposita & 6 & 12 & 12 & 34 & 23 & 87 & 1.98 \\
\hline 珂云眼蝶 Hyponephele kirghisa & 1 & 0 & 0 & 0 & 0 & 1 & 0.02 \\
\hline 仁眼蝶 Eumenis autonoe & 1 & 0 & 2 & 13 & 3 & 19 & 0.43 \\
\hline 侧条槁眼蝶 Karanasa latifasciata & 0 & 0 & 1 & 68 & 60 & 129 & 2.93 \\
\hline 白室岩眼蝶 Chazara heydenreichii & 0 & 1 & 2 & 3 & 36 & 42 & 0.95 \\
\hline 星点弄蝶 Muschampia tessellum & 0 & 5 & 1 & 0 & 3 & 9 & 0.20 \\
\hline *阿波罗绢蝶 Paranssius apollo & 0 & 0 & 2 & 30 & 101 & 133 & 3.02 \\
\hline 金凤蝶 Papilio machaon & 0 & 0 & 0 & 0 & 1 & 1 & 0.02 \\
\hline
\end{tabular}

*国家II级重点保护野生动物 National key protected wildlife level II

科的个体数量最多 $(55.01 \%)$, 云粉蝶为优势种, 占 总个体数量的 $25.18 \%$ 。弄蝶科、绢蝶科、凤蝶科均 只有单一物种, 分别为星点弄蝶 (Muschampia tessellum)、阿波罗绢蝶(Paranssius apollo)和金凤蝶 (Papilio machaon)。

各科物种丰富度水平从高到低依次为蛱蝶科、
灰蝶科、粉蝶科、眼蝶科、弄蝶科、绢蝶科和凤蝶 科。灰蝶科的均匀度指数最高, 为 0.82 。就属级水 平而言，各科间属级多样性从高到低依次为灰蝶 科、蛱蝶科、粉蝶科、眼蝶科、弄蝶科、绢蝶科和 凤蝶科。种级多样性水平和属级基本相同，其中灰 蝶科对研究区域的种级多样性最高, 为 1.70 。弄蝶 
科、风蝶科, 绢蝶科均为单科种, 优势度指数为 1 (表3)。

\section{2 不同生境蝶类群落多样性比较}

吉木萨尔县不同生境蝶类的物种数、多样性指 数和物种丰富度指数存在差异。多样性指数表现为 亚高山草甸 > 山地森林 > 山地草原 > 农田 > 山前荒漠(表4)。农田生境个体占比最高(24.43\%),

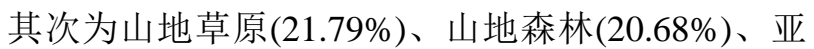
高山草甸 (16.95\%), 山前荒漠中个体数最少 (16.16\%)。农田均匀度指数最高 $(0.73)$, 各科蝶类在 数量上分布较均衡。山前荒漠的优势度指数最高 (0.47), 蝶类组成相对单一, 适应性强的云粉蝶最 多。粉蝶科的斑缘豆粉蝶、豆粉蝶(Colias hyale)、 菜粉蝶(Pieris rapae)、欧洲粉蝶(Pieris brassicae)、 云粉蝶, 眼蝶科的黄祄云眼蝶 (Hyponephele lupina )、居间云眼蝶(Hyponephele interposita)在各 生境均有分布, 表现出较强的适应性和广布性。

在山前荒漠中, 主要分布有云粉蝶、斑缘豆粉
蝶、克豆灰蝶、黄祄云眼蝶，合计占比 $92.12 \%$ 。其 中云粉蝶为优势种 (66.53\%), 豆粉蝶、小红蛱蝶 (Vanessa cardui)、埃灰蝶(Eumedonia eumedon)、萨 眼灰蝶 (Polyommatus sarta)、仁眼蝶 (Eumenis autonoe)、珂云眼蝶(Hyponephele kirghisa)均为稀有 种, 其中珂云眼蝶(Hyponephele kirghisa)仅出现在 该生境。农田中粉蝶科的种类分布较多、数量较大, 占整个生境蝶类总数的 $69.86 \%$, 灰蝶科种类和数量 次之。其中, 斑缘豆粉蝶、菜粉蝶、欧洲粉蝶、云 粉蝶、荨麻蛱蝶为优势种，共占 $79.81 \%$ 。黑纹粉蝶 (Pieris melete)、绿云粉蝶(Pontia chloridice)、单环 蛱蝶 (Neptis rivularis)、灿福蛱蝶 (Fabriciana adippe)、朱蛱蝶 (Nymphalis xanthomelas), 白室岩眼 蝶(Chazara heydenreichii)为该生境稀有种。山地草 原中, 粉蝶科、蛱蝶科、灰蝶科、眼蝶科均分布较 多。其中斑缘豆粉蝶、菜粉蝶、云粉蝶为优势种，共 占56.93\%, 红珠灰蝶(Lycaeides argyrognomon)仅在 该生境出现。山地森林中粉蝶科、眼蝶科种类较多,

表3 新疆吉木萨尔县蝴蝶群落的数量特征

Table 3 Quantitative characteristics of butterfly communities in Jimusaer County, Xinjiang

\begin{tabular}{|c|c|c|c|c|c|c|c|c|c|}
\hline 科名 & 属数 & 种数 & 个体数 & 多样性 & 数 Div & y index & )物种丰富度 & 均匀度指数 & 优势度指数 \\
\hline Famaly & Genera & Species & Individuals & $\overline{H^{\prime}(G)}$ & $H_{(S)}^{\prime}$ & $H_{(G S)}^{\prime}$ & -Species richness $(R)$ & Evenness index $(J)$ & Dominance index $(D)$ \\
\hline 粉蝶科Pieridae & 3 & 9 & 2,421 & 1.04 & 1.57 & 2.61 & 1.03 & 0.71 & 0.28 \\
\hline 蛱蝶科 Papilionidae & 9 & 12 & 921 & 1.20 & 1.40 & 2.69 & 1.61 & 0.56 & 0.38 \\
\hline 灰蝶科 Lycaenidae & 7 & 8 & 377 & 1.63 & 1.70 & 3.33 & 1.18 & 0.82 & 0.20 \\
\hline 眼蝶科 Satyridae & 4 & 6 & 539 & 0.94 & 1.32 & 2.26 & 0.79 & 0.73 & 0.33 \\
\hline 弄蝶科 Hesperiidae & 1 & 1 & 9 & 0 & 0 & 0 & 0 & 0 & 1 \\
\hline 绢蝶科 Parnassiidae & 1 & 1 & 133 & 0 & 0 & 0 & 0 & 0 & 1 \\
\hline 凤蝶科 Papilionidae & 1 & 1 & 1 & 0 & 0 & 0 & 0 & 0 & 1 \\
\hline
\end{tabular}

$H_{(G)}^{\prime}$ : 属级多样性指数; $H_{(S)}^{\prime}$ : 种级多样性指数; $H^{\prime}{ }_{(G S)}$ : 种属级多样性指数

$H^{\prime}{ }_{(G)}$, Diversity index of genus; $H_{(S)}^{\prime}$, Diversity index of species; $H_{(G S)}^{\prime}$, Diversity index of genus and species.

表4 新疆吉木萨尔县不同生境蝴蝶群落的多样性指数

Table 4 Diversity indices of butterfly communities in different habitats in Jimusaer County, Xinjiang

\begin{tabular}{|c|c|c|c|c|c|c|c|c|c|c|c|}
\hline \multirow{2}{*}{$\begin{array}{l}\text { 生境 } \\
\text { Habitat }\end{array}$} & \multirow{2}{*}{$\begin{array}{l}\text { 科数 } \\
\text { Family }\end{array}$} & \multirow{2}{*}{$\begin{array}{l}\text { 属数 } \\
\text { Genera }\end{array}$} & \multirow{2}{*}{$\begin{array}{l}\text { 种数 } \\
\text { Species }\end{array}$} & \multirow{2}{*}{$\begin{array}{l}\text { 个体数 } \\
\text { Individual }\end{array}$} & \multicolumn{4}{|c|}{ 多样性指数 Diversity index $\left(H^{\prime}\right)$} & \multirow{2}{*}{$\begin{array}{l}\text { 物种丰富度 } \\
\text {-Species } \\
\text { richness }(R)\end{array}$} & \multirow{2}{*}{$\begin{array}{l}\text { 均匀度指数 } \\
\text { Evenness } \\
\text { index }(J)\end{array}$} & \multirow{2}{*}{$\begin{array}{l}\text { 优势度指数 } \\
\text { Dominance } \\
\text { index }(D)\end{array}$} \\
\hline & & & & & $H_{(F)}^{\prime}$ & $H_{(G)}^{\prime}$ & $H_{(S)}^{\prime}$ & $H^{\prime}{ }_{(G S)}$ & & & \\
\hline $\begin{array}{l}\text { 山前荒漠 } \\
\text { Piedmont desert }\end{array}$ & 4 & 10 & 15 & 711 & 0.65 & 1.16 & 1.24 & 2.40 & 2.13 & 0.46 & 0.47 \\
\hline $\begin{array}{l}\text { 农田 } \\
\text { Farmland }\end{array}$ & 5 & 15 & 21 & 1,075 & 0.91 & 1.76 & 2.19 & 3.95 & 2.87 & 0.73 & 0.15 \\
\hline $\begin{array}{l}\text { 山地草原 } \\
\text { Mountain grassland }\end{array}$ & 6 & 20 & 26 & 959 & 0.99 & 2.00 & 2.32 & 4.33 & 3.64 & 0.34 & 0.15 \\
\hline $\begin{array}{l}\text { 山地森林 } \\
\text { Mountain forest }\end{array}$ & 5 & 21 & 29 & 910 & 1.35 & 2.39 & 2.79 & 5.17 & 4.11 & 0.41 & 0.08 \\
\hline $\begin{array}{l}\text { 亚高山草甸 } \\
\text { Subalpine meadow }\end{array}$ & 7 & 23 & 33 & 746 & 1.49 & 2.59 & 2.90 & 5.50 & 4.84 & 0.44 & 0.07 \\
\hline
\end{tabular}

$H^{\prime}(F)$ : 科级多样性指数; $H^{\prime}{ }_{(G)}$ : 属级多样性指数; $H^{\prime}(S)$ : 种级多样性指数; $H^{\prime}{ }_{(G S)}$ : 种属级多样性指数

$H_{(F)}^{\prime}$, Diversity index of family; $H_{(G)}^{\prime}$, Diversity index of genus; $H_{(S)}^{\prime}$, Diversity index of species; $H_{(G S)}^{\prime}$, Diversity index of genus and species. 
数量较大, 蛱蝶科次之。其中暗脉粉蝶( Pieris napi )、菖麻蛱蝶、灿福蛱蝶、黄祄云眼蝶、侧条槁 眼蝶 (Karanasa latifasciata) 为优势种, 共占比 $51.98 \%$, 潘豹蛱蝶(Pandoriana pandora)仅在该生境 出现。亚高山草甸中蝶类各科均有分布, 蛱蝶科的 种类和数量最多。其中菖麻蛱蝶、阿波罗绢蝶为优 势种, 分别占比 $13.67 \%$ 和 $13.54 \%$, 大网蛱蝶 (Melitaea scotosia)、玄灰蝶(Tongeia fischeri)为该生 境的特有种。

\section{3 不同生境间蝴蝶种类相似性比较}

各生境间的蝴蝶相似性系数差异较明显(表 5), 山地森林和亚高山草甸间的相似性系数最大, 达到 0.77 , 表现为极相似; 农田和山地草原间的相似性 系数达到 0.74 , 以下依次为山地草原和山地森林 (0.67)、山地草原和亚高山草甸(0.59)、农田和山地 森林(0.56)、农田和亚高山草甸(0.54), 达到中等相 似程度; 山前荒漠和山地森林(0.42)、山前荒漠和农 田(0.38)、山前荒漠和亚高山草甸(0.37), 山前荒漠 和山地草原(0.37)间均表现为中等不相似。

通过不同生境类型蝴蝶物种相似性聚类分析 可以看出：山地森林和亚高山草甸最先聚为一类, 反映出这两类生境的蝶类组成最为相似(图1)。这是 由于两地空间距离较近, 有相似的植被类型(针叶 林、灌木、禾草), 吸引了大量生活习性相似的蝶类 聚集。农田和山地草原在相似性系数为 0.74 时聚为 一类, 两地蝴蝶以粉蝶科和蛱蝶科为主。在调查过 程中发现在山地草原开垦农田种植农作物较多, 造 成两生境的植被类型单一, 生境破坏也较为严重。 山前荒漠与其他两组生境蝶类组成差异较大, 因此 单独归为一类。该生境植被稀疏, 主要由耐旱的旱 生小乔木、灌木组成, 平均气温较高且距水源地远, 因而和其他生境的蝶类物种相似性较低。

\section{4 不同海拔梯度蝴蝶群落多样性比较}

吉木萨尔县蝴蝶群落的分布与海拔总体上呈 线性相关关系, 即随着海拔上升, 人为干扰减少, 生境破碎化程度减轻, 研究区域内的蝴蝶物种数、 多样性指数、物种丰富度和均匀度指数整体上呈上 升趋势(图2)。个体数在不同海拔区域变化较大, 但 总体上从1,000-1,900 m呈单峰分布, 这是因为在该 海拔范围内, 生境相对复杂且较为完整, 人为干扰 程度适中, 利于增加植物丰富度, 适宜蝴蝶生存。 海拔 $1,000 \mathrm{~m}$ 以下主要生境为山前荒漠和农田, 特
殊的气候环境和以十字花科为主要农作物的单一 植被类型，使得蝴蝶优势度指数最高。

\section{5 蝴蝶群落的时间动态变化}

2016-2018 年蝴蝶的物种数和个体数整体变化 趋势基本一致, 表现为由 5 月开始逐步增加, 在 7 月达到最大值后逐步减少(图 3)。各月份的蝴蝶物种 数逐年略有增加, 但个体数逐年减少。其中 2016 年 7 月调查中发现并记录的蝴蝶个体最多(1,001 号), 5 月最少(11 号); 2018 年 7 月蝴蝶物种数最多(24 种), 2016 年 5 月最少(2 种)。粉蝶科、蛱蝶科、灰蝶科 于 5 月开始发生, 弄蝶科、绢蝶科、凤蝶科从 6 月 中旬开始发生。其中粉蝶科、蛱蝶科、灰蝶科、眼 蝶科的物种数、个体数均在 7 月达到最大, 进入 8 月下旬后数量明显减少。

该地区 3 年的蝴蝶多样性指数变化趋势基本保 持一致(图 4), 即 5 月最低(0.56), 后随着 6 月和 7 月 间平均气温增高, 雨量增大, 且多数植物处于开花 期，因而蝴蝶的物种组成、丰度和多度在 6 月和 7 月达到高峰。其中每年 5 月蝴蝶的优势度指数最大 (0.51), 与之相对应的均匀度指数在每年的 7 月达到 最大值 $(0.78)$ 。从蝶类组成来看, 伴随着 5 月农田、 山地草原的十字花科、豆科、蓄薇科植物陆续开始 生长, 粉蝶科的数量开始上升; 6 月菖麻、大麻、大 蓟等植物较繁盛, 蛱蝶科的物种数和个体数开始上 升; 7 月各科蝶类的物种数和个体数在各生境均基 本达到最大值, 至 8 月多数植物进入结实期, 蝴蝶 的数量迅速减少。

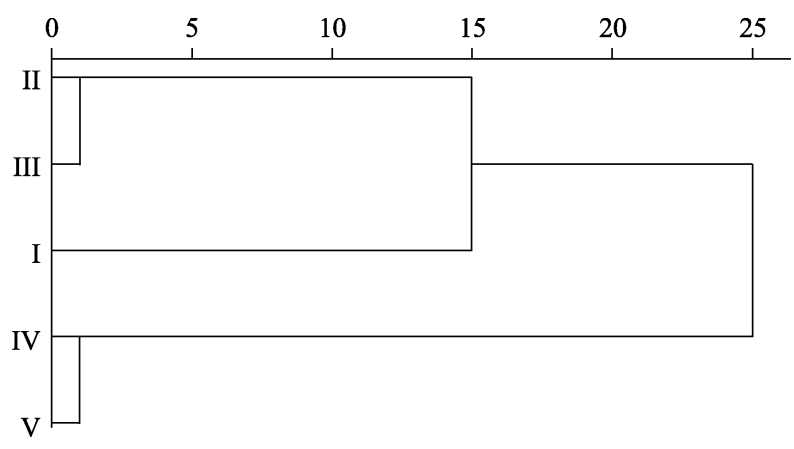

图1 新疆吉木萨尔县不同生境类型蝴蝶物种相似性聚类分 析。I: 山前荒漠; II: 农田; III: 山地草原; IV: 山地森林; V: 亚高山草甸。

Fig. 1 Similarity clustering analysis of butterfly species in different habitats in Jimusaer County, Xinjiang. I, Piedmont desert; II, Farmland; III, Mountain grassland; IV, Mountain forest; V, Subalpine meadow. 
表5 吉木萨尔县不同生境中相同蝴蝶种数(对角线上)及相似性系数(对角线下)

Table 5 Number of the shared species (above diagonal) between two habitats and similarity coefficient (below diagonal) in Jimusaer County

\begin{tabular}{llllll}
\hline 生境 Habitat & $\begin{array}{l}\text { 山前荒漠 } \\
\text { Piedmont desert }\end{array}$ & $\begin{array}{l}\text { 农田 } \\
\text { Farmland }\end{array}$ & $\begin{array}{l}\text { 山地草原 } \\
\text { Mountain grassland }\end{array}$ & $\begin{array}{l}\text { 山地森林 } \\
\text { Mountain forest }\end{array}$ & $\begin{array}{l}\text { 亚高山草甸 } \\
\text { Subalpine meadow }\end{array}$ \\
\hline 山前荒漠 Piedmont desert & & 10 & 11 & 13 & 13 \\
农田 Farmland & 0.38 & & 20 & 18 & 19 \\
山地草原 Mountain grassland & 0.37 & 0.74 & & 22 & 22 \\
山地森林 Mountain forest & 0.42 & 0.56 & 0.67 & 0.77 & 27 \\
亚高山草甸 Subalpine meadow & 0.37 & 0.54 & 0.59 & & \\
\hline
\end{tabular}
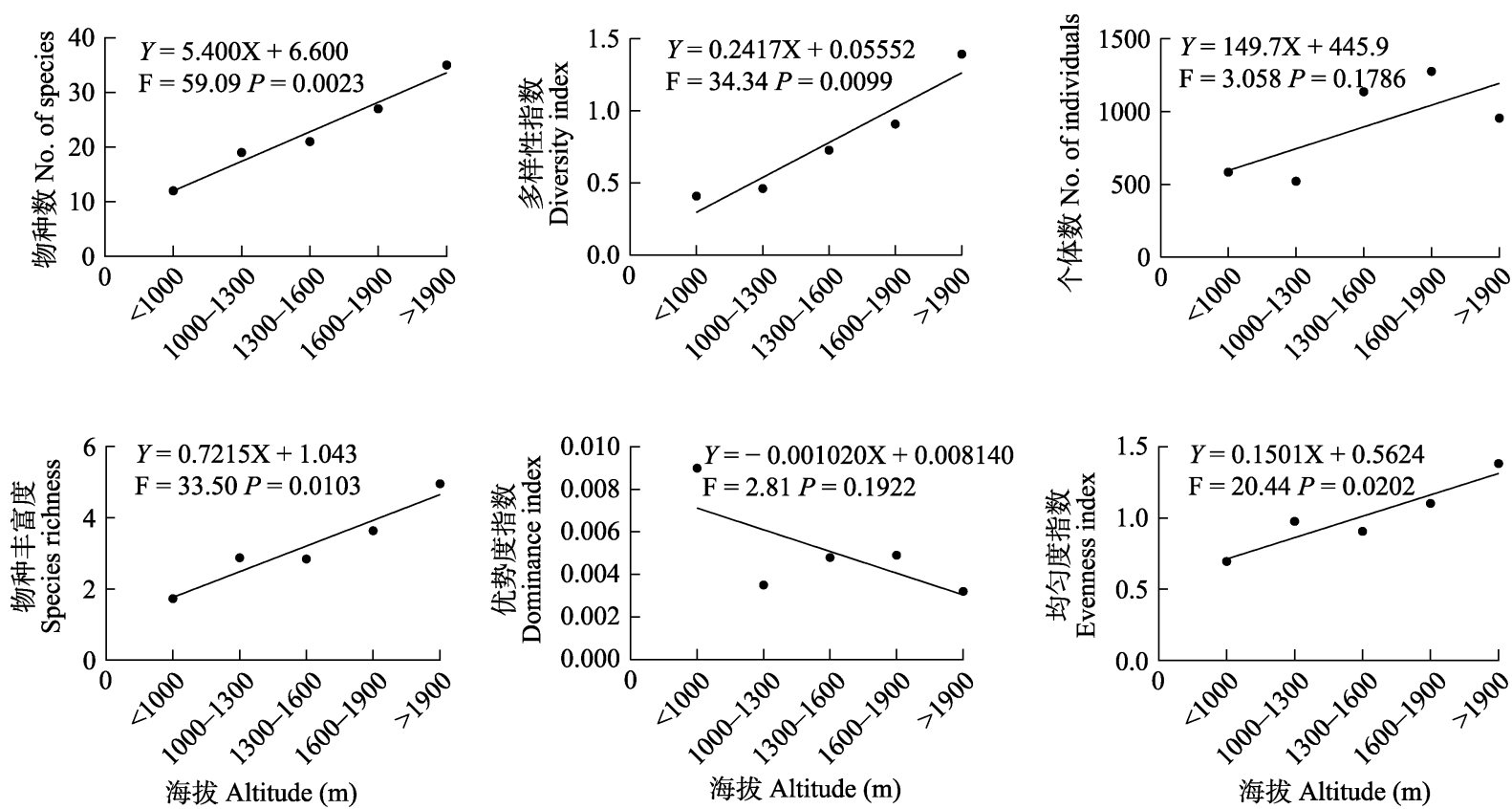

图2 新疆吉木萨尔县不同海拔段蝴蝶群落多样性比较

Fig. 2 Diversity index of butterfly communities with different altitude in Jimusaer County, Xinjiang

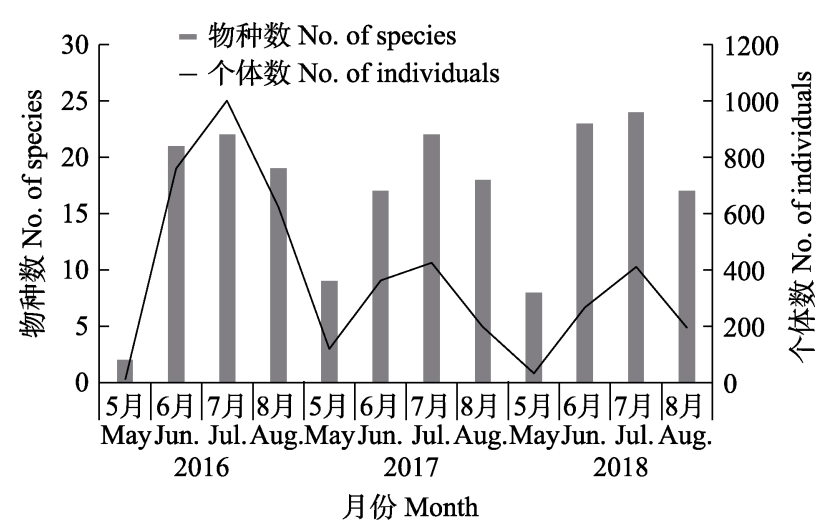

图3 新疆吉木萨尔县蝴蝶物种数和个体数的时间动态

Fig. 3 Temporal dynamics of species and individuals number in Jimusaer County, Xinjiang

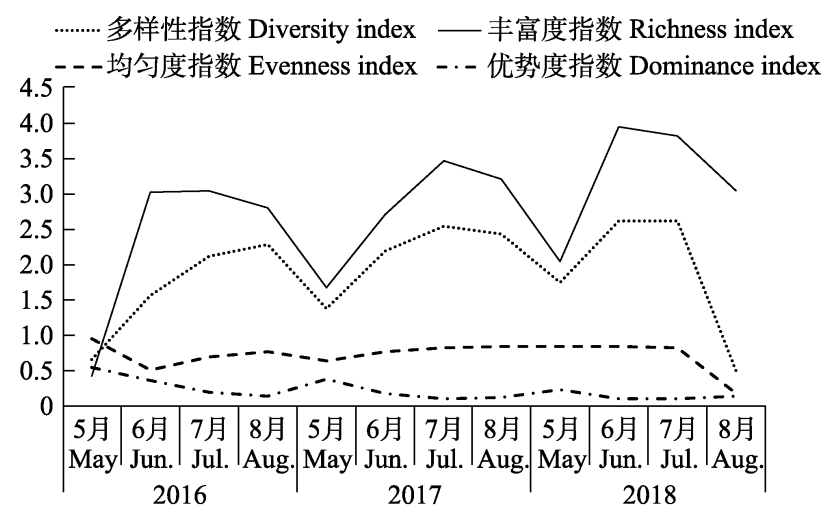

月份 Month

图4 新疆吉木萨尔县蝴蝶群落多样性 $\left(H^{\prime}\right)$ 、丰富度 $(R)$ 、均 匀度 $(J)$ 、优势度 $(D)$ 的时间动态

Fig. 4 Temporal dynamics of diversity $\left(H^{\prime}\right)$, richness $(R)$, Evenness $(J)$ and dominance index in Jimusaer County, Xinjiang 


\section{3 讨论}

\section{1 吉木萨尔县蝴蝶群落的组成特征}

本研究区域处于天山北麓地带东段, 气候环境 复杂, 海拔落差大, 生境异质性高, 物种丰富(熊嘉 武等, 2015)。通过调查研究, 发现吉木萨尔县蝶类 7 科 26 属 38 种，占新疆已知蝴蝶种类的 $14.96 \%$ 。该 研究结果与张金等(2013)于 2006-2008 年对天山东 部乌鲁木齐县等地蝶类的研究结果有相同蝶类 21 种, 相似性系数为 0.26 ; 与黄人唫和孙庆文 (1984)、郭婕等(2019)对天山西部霍城县等地蝶类的 研究相比共有相同蝶类 22 种, 相似性系数 0.27 ; 与 Korb (2009)对天山北部部分地区蝶类研究结果相 比, 共有相同蝶类 17 种, 相似性系数 0.08 ; 与吕学 农等(1999)对阿勒泰地区蝴蝶种类调查研究结果相 比, 共有相同蝶类 25 种, 相似性系数 0.20 。对比中 可看出该地区蝴蝶分布具有其独特性, 且一定程度 上补充了天山东部的蝴蝶资源。

在研究区域内人工大面积种植的油菜、白菜等 十字花科植物是云粉蝶个体数量最多的主要原因。 蛱蝶科物种数最多, 但各物种间的数量相差较大, 数量占优的菖麻蛱蝶高达 531 只, 而潘豹蛱蝶仅有 1 只, 主要原因是研究区域内菖麻蛱蝶的唯一寄主 植物菖麻分布较广且长势较旺。灰蝶科物种数较多 且各物种间的数量相差最小, 在一定程度上说明灰 蝶科适宜生存的生境较为稳定, 但其主要寄主蝶形 花科植物在研究区域分布较少, 从而导致灰蝶在数 量上并不占优势。

\section{2 不同生境对蝴蝶群落组成的影响}

研究结果表明生境的变化对蝶类的分布具有 显著影响。各生境的生态质量和植被类型与蝴蝶群 落的分布表现出高度一致性。农田中大面积种植的 农作物如油菜、玉米等是粉蝶科的主要寄主植物, 眼蝶科喜林荫潮湿, 因而在山地森林多有分布, 绢 蝶和凤蝶体型大、善飞行、耐寒力强, 多分布在海 拔较高、气温相对较低的亚高山草甸。蛱蝶科主要 寄主植物在不同海拔均有分布, 且蛱蝶生活习性多 样, 既有喜欢活动于开阔地带的, 也有喜欢活动于 密林中的; 有喜欢吸食花蜜的, 也有喜欢吸取树干 汁液的, 因而在各生境均有分布。

生境破碎化是导致物种数量及多样性降低的 主要原因(武正军和李义明, 2003)。其中不同生境的
植被类型、海拔范围、人为干扰程度对蝴蝶群落的 分布及多样性起到至关重要的作用(李密, 2011)。本 研究中, 蝶类群落的物种数、多样性指数从海拔 $1,000 \mathrm{~m}$ 以下的山前荒漠至海拔 2,000 $\mathrm{m}$ 以上的亚高 山草甸呈逐渐上升趋势，该结果与胡冰冰等(2010) 的研究结果一致, 与陈振宁等(2006)、郭婕等(2019) 的研究结论略有不符。原因在于吉木萨尔县低海拔 区域人工开唇、围栏放牧情况严重, 生境破碎化程 度高，导致植被类型较为单一。而处于高海拔区域 的山地森林、亚高山草甸虽然温度较低, 但人为干 扰因素少、植被丰富度高，可以给蝶类生存栖息提 供更加适宜的环境(Beck et al, 2002)。此外受到全球 气候变化的影响，分布在中低海拔区域的部分蝶类 会向高海拔的高山草甸迁移，使得高海拔生境的物 种丰富度增加, 低海拔生境的物种多样性逐渐减少 (Christy, 2005; Ghazala \& Cesar, 2005; Wilson et al, 2007)。

\section{3 蝴蝶的保护与利用}

吉木萨尔县独特的地理位置和生态环境, 使其 拥有丰富的动植物资源, 为蝶类提供了良好的栖息 环境。近年来，随着旅游业的开发、围栏放牧、开 艮农田等人类活动的日渐频繁，导致该地区生境破 碎化程度加深，植物多样性不断降低。阿波罗绢蝶 作为该地区高海拔样段的代表种，在被列为II级国 家野生保护动物后，当地保护区相关部门加大了对 其保护力度(李都, 2002), 在连续观测的 3 年内个体 数量逐步增加。但在同海拔区域，未发现有其他常 见绢蝶科物种, 如以前常见的天山绢蝶和曾经记录 的珍珠绢蝶(Parnassius orleans), 主要原因一是阿 波罗绢蝶被列为保护动物后, 其他绢蝶科物种成为 主要盗猎对象; 二是与绢蝶科的主要寄主景天科植 物有关，该类植物在天山高海拔区分布广泛，是重 要的中药材, 被严重盗挖后导致了绢蝶科物种数量 锐减(于非等, 2012)。

近3年的调查研究表明该地区的蝴蝶个体数量 呈现下降趋势, 进一步说明了生态环境对于物种多 样性具有至关重要的作用。为加强该地区蝶类生物 多样性保护，提出以下建议：(1)对于吉木萨尔县乃 至整个东天山地区的蝶类多样性的保护工作必须 从保护天然生境开始, 针对该地区进行的旅游业开 发、农牧业生产、工厂建设等应进行评估考核，以 更好地维持区域环境动态平衡; (2)要加强本地蝶类 
资源调查力度，加大该地区蝴蝶动态监测频率，为 该地区的环境动态变化提供更多的理论依据; (3)要 加强宣传教育工作，通过多种途径宣传国家有关于 野生动物保护的法律、法规和制度。有关部门要加 强监督管理力度，坚决禁止野生动物的采捕和非法 交易。

\section{参考文献}

Beck J, Schulze CH, Linsenmair KE, Fiedler K (2002) From forest to farmland: Diversity of geometrid moths along two habitat gradients on Borneo. Journal of Tropical Ecology, 18, 33-51.

Chou I (2000) Monographia Rhopalocerorum Sinensium. Henan Science and Technology Press, Zhengzhou. (in Chinese) [周尧 (2000) 中国蝶类志. 河南科学技术出版 社, 郑州.]

Cao MC, Le ZF, Lei JC, Xu HG (2013) Approaches to assessment of global biodiversity and advancements in their researches. Journal of Ecology and Rural Environment, 29, 8-16. (in Chinese with English abstract) [曹铭昌, 乐志芳, 雷军成, 徐海根 (2013) 全球生物多样性评估方法及研 究进展. 生态与农村环境学报, 29, 8-16.]

Chen ZN, Zeng Y, Bao M, Ma JX, Ke J (2006) Butterfly diversity in different habitat types at the Huzhu Northern Mountain National Forest Park, Qinghai. Biodiversity Science, 14, 517-524. (in Chinese with English abstract) [陈 振宁，曾阳，鲍敏，马继雄，柯君 (2006) 青海互助北山 国家森林公园不同生境的蝶类多样性研究. 生物多样性, 14, 517-524.]

Christy MM (2005) Elevational gradients in diversity of small mammals. Ecology, 86, 366-372.

Dan ZC, Bao M, Ma CX, Li LL, Hao HW, Cheng F, Cai XZM, Chen ZN (2018) Community structure and butterfly diversity in different habitat types in the Qinghai Yushu plateau. Acta Ecologica Sinica, 38, 7557-7564. (in Chinese with English abstract) [旦智措, 鲍敏, 马存新, 李雷雷, 郝 会文, 成帆, 才项卓玛, 陈振宁 (2018) 青海玉树高原不 同生境类型蝶类群落结构与多样性. 生态学报, 38, 7557-7564.

Fang LJ, Xu HG, Guan JL (2013) History and present status of butterfly monitoring in Europe and related development strategies for China. Chinese Journal of Applied Ecology, 24, 2691-2698. (in Chinese with English abstract) [房丽君, 徐海根, 关建玲 (2013) 欧洲蝴蝶监测的历史、现状与我 国的发展对策. 应用生态学报, 24, 2691-2698.]

Fu WD, Yao YL, Li YC (2007) Characteristics of climate change in Jimusar County of Xinjiang for recent 45 years. Meteorological Monthly, 33(6), 96-101. (in Chinese with English abstract) [傅玮东, 姚艳丽, 李迎春 (2007) 新疆 吉木萨尔县 45 年气候变化特征分析。气象, 33(6), 96-101.]
Ghazala S, Cesar AP (2005) Frugivorous butterfly species in tropical forest fragments: Correlates of vulnerability to extinction. Biodiversity and Conservation, 14, 1137-1152.

Guo J, Wu W, Jiang LL, Hu HY (2019) Diversity of butterflies in Huocheng County, Xinjiang. Xinjiang Agricultural Sciences, 56, 446-456. (in Chinese with English abstract) [郭婕, 吴卫, 蒋玲玲, 胡红英 (2019) 新疆霍城蝴蝶群落 多样性. 新疆农业科学, 56, 446-456.]

Hu BB, Li HH, Liang ZP, Zhao TJ, Ren XB (2010) Diversity and fauna of butterflies in Baxian Mountain State Nature Reserves. Acta Ecologica Sinica, 30, 3226-3238. (in Chinese with English abstract) [胡冰冰, 李后魂, 梁之聘, 赵铁建，任秀柏 (2010) 八仙山自然保护区蝴蝶群落多 样性及区系组成. 生态学报, 30, 3226-3238.]

Hu HY, Huang RX (2012) Primary Color Atlas of Xinjiang Insects. Xinjiang University Press, Urumqi. (in Chinese) [胡 红英, 黄人金金 (2012) 新疆昆虫原色图鉴. 新疆大学出版 社，乌鲁木齐.]

Huang RX, Sun QW (1984) Butterflies of west part of Tianshan Mountains from Xinjiang and their vertical distribution. Journal of Xinjiang University (Natural Science Edition), 2, 93-96. (in Chinese) [黄人金金，孙庆文 (1984) 新疆天山西部的蝶类及其垂直分布. 新疆大学学报(自然 科学版), 2, 93-96.]

Huang RX, Zhou H, Li XP (2000) Xinjiang Butterfly. Xinjiang Science and Technology Press, Urumqi. (in Chinese) [黄人 金金, 周红, 李新平 (2000) 新疆蝴蝶. 新疆科技卫生出版 社, 乌鲁木齐.]

Ji TT (2019) The Study of Butterfly Species Diversity and Community Dynamics in Mt. Tianmu of Zhejiang Province. Central South University of Forestry and Technology, Changsha. (in Chinese with English abstract) [姬婷婷 (2019) 浙江天目山蝴蝶多样性及群落动态规律研究. 中 南林业科技大学, 长沙.]

Korb SK (2009) The butterfly fauna (Lepidoptera, Rhopalocera) of the Kungey Ala-Too Mt. Range (Northern Tien Shan). Entomological Review, 88, 1079-1089.

Kremen C (1992) Assessing the indicator properties of species assemblages for natural areas monitoring. Ecological Applications, 2, 203-217.

László R, Schmitt T (2011) Are butterflies and moths suitable ecological indicator systems for restoration measures of semi-natural calcareous grassland habitats? Ecological Indicators, 11, 1040-1045.

Li D (2002) Parnassius apollo (Linnaeus). Bulletin of Biology, 12, 25. (in Chinese) [李都 (2002) 阿波罗绢蝶. 生物学通 报, 12, 25.]

Li G, Li JS (2014) Technical Manual of Biodiversity Monitoring. Environmental Science Press, Beijing. (in Chinese) [李果, 李俊生 (2014) 生物多样性监测技术手 册. 环境科学出版社, 北京.]

Li M (2011) Studies on Conservation Biology of Butterfly in Wuyunjie National Nature Reserve. PhD dissertation, 
Agricultural University of Hunan, Changsha. (in Chinese with English abstract) [李密 (2011) 乌元界国家级自然保 护区蝴蝶保护生物学研究. 博士学位论文, 湖南农业大 学, 长沙.]

Li XS, Zhang YL, Fang JH (2011) A butterfly hotspot in western China, its environmental threats and conservation. Journal of Insect Conservation, 15, 617-632.

Liu CR, Ma KP, Lü YL, Kang YL (1998) Measurement of biotic community diversity VI. The statistical aspects of diversity measures. Chinese Biodiversity, 2, 229-239. (in Chinese with English abstract) [刘灿然, 马克平, 吕延华, 康永亮 (1998) 生物群落多样性的测度方法VI. 与多样 性测度有关的统计问题. 生物多样性, 2, 229-239.]

Lü XN, Duan XD, Wang WG, Li W, Shi HT, Gou BH (1999) A study on species and vertical distribution of butterflies in Altai Mountains, Xinjiang, China. Chinese Biodiversity, 7, 8-14. (in Chinese with English abstract) [吕学农, 段晓东, 王文广, 李伟, 师海涛, 苟宝华 (1999) 阿勒泰山蝴蝶种 类调查及其垂直分布的研究. 生物多样性, 7, 8-14.

Ma FZ, Xu HG, Chen MM, Tong WJ, Wang CB, Cai L (2018) Progress in construction of China Butterfly Diversity Observation Network (China BON-Butterflies). Journal of Ecology and Rural Environment, 34, 27-36. (in Chinese with English abstract) [马方舟, 徐海根, 陈萌萌, 童文君, 王晨涁, 蔡蕾 (2018) 全国蝴蝶多样性观测网络(China BON-Butterflies)建设进展. 生态与农村环境学报, 34, 27-36.]

Ma KP (1994) Measurement of biotic community diversity I: $\alpha$ diversity (Part 1). Chinese Biodiversity, 2, 162-168. (in Chinese) [马克平 (1994) 生物群落多样性的测度方法: I $\alpha$ 多样性的测度方法(上). 生物多样性, 2, 162-168. ]

Mihindukulasooriy MWDM, Ranawana KB, Majer JD (2014) Comparison of butterfly diversity in natural and regenerating forest in a biodiversity conservation site at Maragamuwa, Sri Lanka. Journal of Biodiversity and Environmental Sciences, 5, 387-391.

Mulder CPH, Bazeley WE, Dimitrakopoulos PG, Andy H (2004) Species evenness and productivity in experimental plant communities. Oikos, 107, 50-63.

Nelson SM (2007) Butterflies (Papilionoidea and Hesperioidea) as potential ecological indicators of riparian quality in the semi-arid western United States. Ecological Indicators, 7, 469-480.
Pimm SL, Russell GJ, Gittleman JL (1995) The future of biodiversity. Science, 269, 347-350.

Wang M, Fan XL (2002) Chinese Lycaenidae. Henan Science and Technology Press, Zhengzhou. (in Chinese) [王敏, 范 骁凌 (2002) 中国灰蝶志. 河南科学技术出版社, 郑州.]

Wilson RJ, Gutierrez D, Gutierrez J, Monserrat VJ (2007) An elevational shift in butterfly species richness and composition accompanying recent climate change. Global Change Biology, 13, 1873-1887.

Wu CS, Xu YF (2017) Butterflies of China. The Straits Publishing \& Distributing Group, Fuzhou. (in Chinese) [武 春生, 徐垤峰 (2017) 中国蝴蝶图鉴. 海峡出版发行集 团, 福州.]

Wu ZJ, Li YM (2003) Effects of habitat fragmentation on survival of animal population. Acta Ecologica Sinica, 23, 2424-2435. (in Chinese with English abstract) [武正军, 李 义明 (2003) 生境破碎化对动物种群存活的影响. 生态 学报, 23, 2424-2435.]

Wu ZY (1980) Vegetation of China. Science Press, Beijing. (in Chinese) [吴征镒 (1980) 中国植被. 科学出版社, 北京.]

Xu HG, Cao MC, Wu Y, Cai L, Cao Y, Ding H, Cui P, Wu J, Wang Z, Le ZF, Lu XQ, Liu L, Li JQ (2017) Optimized monitoring sites for detection of biodiversity trends in China. Biodiversity and Conservation, 26, 1959-1971.

Xiong JW, Ma M, Hu HY (2015) Comprehensive Scientific Investigation of the Mountainous Areas in Eastern Tianshan, Xinjiang. China Forestry Publishing House, Beijing. (in Chinese) [熊嘉武, 马鸣, 胡红英 (2015) 新疆天山东部山 地综合科学考察. 中国林业出版社, 北京.]

Yu F, Wang H, Wang SK, Zhang Q, Ji R (2012) Response of Parnassius apollo population and vertical distribution to climate warming. Acta Ecologica Sinica, 32, 6203-6209. ( in Chinese with English abstract) [于非, 王晗, 王绍坤, 张强, 季荣 (2012) 阿波罗绢蝶种群数量和垂直分布变 化及其对气候变暖的响应. 生态学报, 32, 6203-6209.]

Zhang X, Hu HY, Lü ZZ (2013) Butterfly diversity and vertical distribution in eastern Tianshan Mountain in Xinjiang. Acta Ecologica Sinica, 33, 5329-5338. (in Chinese with English abstract) [张金金, 胡红英, 吕昭智 (2013) 新疆东部天山蝶 类多样性及其垂直分布. 生态学报, 33, 5329-5338.]

(责任编委: 朱朝东 责任编辑: 时意专)

\section{附录 Supplementary Material}

附录1 新疆吉木萨尔县蝴蝶物种各生境分布汇总

Appendix 1 Summary of distribution of butterfly species in different habitats in Jimusaer County, Xinjiang

http://www.biodiversity-science.net/fileup/PDF/2020065-1.xlsx 